\title{
Economic Decisions and Simon's Notion of Bounded Rationality
}

\author{
Daniele Schilirò $^{1}$ \\ ${ }^{1}$ Department of Economics, University of Messina, Piazza Pugliatti, 1, 98122 Messina, Italy \\ Correspondence: Daniele Schilirò, Department of Economics, University of Messina, Piazza Pugliatti, 1, 98122 Messina, \\ Italy.
}

Received: May 11, 2018

doi:10.5539/ibr.v11n7p64

\author{
Accepted: June 1, 2018 \\ Online Published: June 15, 2018 \\ URL: https://doi.org/10.5539/ibr.v11n7p64
}

\begin{abstract}
Decision making in economics has been always intertwined with the concept of rationality. However, neoclassical economic literature has been dominated by a specific notion of rationality, namely, perfect rationality, characterized by the assumption of consistency and by the maximization hypothesis. Herbert Simon, in his long research activity, questioned this concept of perfect or global rationality, suggesting a different vision, based on empirical evidence and regarding an individual's choices. He challenged the neoclassical theory of global rationality, suggesting his notion of bounded rationality, a satisficing (instead of optimizing) behavior, and the relevance of procedural rationality to understand the process of thought of decision makers.

Thus, this paper focuses on Simon's notion of bounded rationality, since bounded rationality remains the hallmark of his theoretical contribution. First, the paper examines the economic decision process in the neoclassical theory and Simon's notion of bounded rationality. Then, it analyzes in depth Simon's behavioral model of rational choice, underlining the relevance of satisficing behavior and procedural rationality. Finally, it suggests an assessment of the concept of bounded rationality.
\end{abstract}

Keywords: bounded rationality, economic decisions, expected utility, global rationality, procedural rationality, satisfying behavior

\section{JEL Classification: D01; D8; D9; B31}

\section{Introduction}

The concept of rationality is central to economics. This concept passed through various stages, from the strong version of rationality of classical utilitarian economists to the weaker concept of revealed preference theory. However, economic literature has been dominated by the concept of rationality and its consistency feature, and by the maximization hypothesis.

Herbert Simon is considered one the fathers of behavioral economics and a pioneer of artificial intelligence (Note 1). In his long research activity in many scientific fields, including economics, he challenged mainstream economics by postulating, as Sent (2005) states, that "human rationality is bounded, due to external and social constraints, and internal and cognitive limitations" (p.227).

Simon developed the analysis of decision making related to both individuals and organizations. His theoretical contribution to the topic of economic decisions is the result of an interdisciplinary approach where economics, psychology, cognitive science, and organizational theory interact. Thus, Simon's notion of bounded rationality became the central topic of this interaction between these discipline fields.

This paper focuses on Simon's notion of bounded rationality, defined as the limitations and difficulties of the decision maker to behave in the way the traditional rational choice theory assumes, due to his insufficient cognitive and computational capacities to process all the relevant information.

Undoubtedly, many other authors adopted the label of bounded rationality in the literature to indicate some form of departure from rational choice theory. However, Simon used the term to refer to a more simplified vision of human decision making, by which he linked psychological factors to the decision maker's economic behavior, and, thus, built his theoretical view on an empirical methodology. As a result, bounded rationality remains the hallmark of his theoretical contribution.

The reminder of the paper is organized as follows. The second section examines the economic decision process in the neoclassical theory. The third section discusses Simon's theory of bounded rationality and its key 
components. The fourth section analyzes Simon's behavioral model of rational choice in depth, underlining the relevance of satisficing behavior and the environment. The fifth section examines Simon's procedural rationality and its role in the bounded rationality theory. The last section suggests an assessment of the concept of bounded rationality in Simon. Conclusions end the paper.

\section{Economic Decisions and Bounded Rationality}

In classical and neoclassical economics, rationality has a specific meaning. A man is rational since he has a coherent criterion of choice. In addition, this man is characterized by omniscient rationality. The neoclassical theory assumes that the decision maker has a comprehensive and consistent utility function, knows all the alternatives that are available for choice, can compute and choose the alternative that maximizes utility, or, in the case of uncertainty, compute the subjective expected value of utility which is associated with each alternative, and choose the alternative that maximizes expected utility.

The theory of rational choice under uncertain outcomes describes the choice as a result of a rational process driven by a single cognitive process, which is characterized by a set of assumptions, and it orders the decisions on the basis of expected utility. Thus, expected utility theory represents the normative model of rational choice. Furthermore, statistical decision theory and game theory have contributed, embracing uncertainty, risk, and imperfect information, to strength the neoclassical view of rational choice. As a result, the standard of rationality in economics becomes the maximization of subjective expected utility-a combination of von Neumann-Morgenstern preferences and a Bayesian belief structure (Edwards, 1954; Schilirò, 2012, 2017). Finally, computer modelling and engineering techniques have strengthened the decision analysis together with Bayesian statistics (Howard, 1960) (Note 2).

Simon criticizes this theoretical approach and the lack of empirical hypotheses on an individual's behavior that underlies it. He has a different idea of rationality and proposes a theory that derives from limited or bounded rationality. Simon's approach emphasizes the limitations of the cognitive system and the change of cognitive processes due to expertise. Simon supports the view that the theory of rationality needs more articulated empirical hypotheses, that is the need for more extensive observations of real behavior in the decision-making process of human beings. In fact, his different idea of rationality starts from empirical observation regarding, for example, the way in which companies behave to decide prices and establish profits, or about how individuals behave in their choices as consumers or in the labor market. In order to develop such a theory, he refers to psychology, to the method that psychology adopts to study the behavior of individuals, to the attention of psychology towards the decisional processes, and to reasoning. Simon does not look at the goal (maximization of profit), but at the process that leads to an objective narrative.

\section{Simon's Notion of Bounded Rationality}

According to Herbert Simon (1979), the classical theory of omniscient (perfect) rationality is simple and straightforward, since it is based on very strong assumptions. These assumptions are: knowledge of all the alternatives that are open to choice; ability to compute the consequences that will follow on each of the alternatives; certainty in the decision maker's present and future evaluation of these consequences. Therefore, the shape of the environment is determined, and, with the assumption of omniscient rationality, such theory fully determines the decision maker's behavior.

Already in the first edition of Administrative Behavior Simon, (1947), rejected the notion of an omniscient "economic man" capable of making decisions that bring the greatest benefit possible, and set out an alternative approach based on the idea of an administrative man who satisfices (i.e., looks for a course of action that is satisfactory or "good enough"), instead of maximizing. Simon (1947) aims to establish the difference between theoretical behavior and actual behavior, verifying in practice the direct inapplicability of the neoclassical theory (Barros, 2010).

In Administrative Behavior, the concept of bounded rationality does not appear explicitly, but as a residual category-rationality is limited or bounded, when it falls short of omniscience. The failures of omniscience are largely failures of knowing all the alternatives, uncertainty about relevant exogenous events, and inability to calculate consequences (Simon, 1979).

In the 1950s, Simon $(1955,1956,1957,1959)$ devised a more positive and formal characterization of the mechanisms of choice under conditions of bounded rationality, taking into account not only the man's economic behavior, but also his environment. Simon pointed out that global rationality (Note 3) in the neoclassical theory requires a complete knowledge and anticipation of the consequences that will follow on each choice. With global rationality, no psychological theory is needed other than a theory of wants and needs. In particular, global 
rationality implies no need for a theory of human behavior, that is, understanding human thought processes in order to carry out economy analysis. It is sufficient to know how people ought to behave, since the neoclassical theory assumes that people will do things that are objectively rational.

Simon's major idea is to replace the unrealistic representation of the economic man, who is characterized by global rationality, with a behavior that is still rational, but that is compatible with the access to the information and the computational capacities that the man actually possesses in the environment where he lives. Thus, Simon develops his concept of bounded rationality, which represents the key interface between his works in economics and psychology (Schilirò, 2013). As Klaes and Sent (2005) state:

"Simon advanced the concept of bounded rationality in an effort to include the whole range of limitations on human knowledge and human computation that prevent economic actors in the real world from behaving in ways that approximate the predictions of the neoclassical theory" (p.38).

In Models of Man, Simon (1957) calls his alternative approach the "principle of bounded rationality". Actually, the capacity of the human mind for formulating and solving complex problems is very small, compared with the size of the problems (Simon, 1957, p.198). Then, man has limited or bounded rationality, in the sense that he lacks both the information and the computational capacities to be globally rational (Simon, 1987). He also lives in a world which offers a set of objectively available behavior alternatives, but a more limited set of "perceived" behavior alternatives to which he can respond (Simon, 1957, 1997a). Man's behavior cannot be predicted just from the characteristics of the objective environment, but also from information about his perceptual and cognitive process. In Simon's view, man intends to be rational, but may fail, then it is important to know something about his cognitive and emotional architecture.

As Simon (1972) explained:

"theories that incorporate constraints on the information-processing capacities of the actor may be called theories of bounded rationality" (p.162).

According to Simon (1959), paradoxically, the notion of bounded rationality originates from a broadening of the definition of rationality that encompass goal conflict and uncertainty. Simon (1972) identifies a variety of ways to assume limits of rationality, such as risk and uncertainty, incomplete information about alternatives, and complexity. Also, he (Simon,1959) points out that, even with the powerful new tools and machines, most real-life choices still lie beyond the reach of maximizing techniques, unless of drastic approximations. Thus, in real life, rationality must involve something simpler than maximization of utility or profit.

In this less ambitious vision of human decision making, bounded rationality describes this process and the results it brought as "satisficing" (Note 4). In this regard, Simon (1972) explained that

"the Scottish word satisficing (= satisfying) has been revived to denote problem solving and decision making that sets an aspiration level, searches until an alternative is found that is satisfactory by the aspiration level criterion, and selects that alternative" (p. 168) (Note 5).

Decision makers satisfice since they go with first satisfactory course of action, taking shortcuts, rather than continuing to search for the best. Thus, in Simon's view, the term "heuristic" takes on a positive connotation.

The notion of bounded rationality, therefore, asserts that decision makers' cognitive capabilities are not always sufficient to find optimal solutions to complex real-life problems, leading decision makers to find satisfactory and suboptimal outcomes (Mallard, 2016, p. 2).

Yet, according to Simon $(1959$, p. 265), models of satisficing behavior are richer than models of maximizing behavior, because they treat not only of equilibrium, but also of the method of reaching it. However, as Simon (1990, p.9) explains, satisficing is a weak method. This implies that the search process is halted, when a solution meets our expectations.

The main thrust of Simon's model of bounded rationality is that specific constraints occur and force a decision maker to be less than rational. The basic assumptions of his model are: Decision makers select the first alternative that is satisfactory; their conception of the world is simple; furthermore, decisions are made without determining all the alternatives by rules of thumb or shortcuts (heuristics) (Simon, Egidi, Viale, \& Marris, 1992) (Note 6).

In Simon's work, economics and psychology are intertwined. The formation of expectations is precisely a case in point, wherein psychologists and economists applied a wide variety of empirical and theoretical approaches. Actually, Simon's notion of bounded rationality moves in the opposite direction of rational expectations. In the latter, the agent should be able to forecast and profit/utility-maximize, whereas in the bounded rationality view decision makers do not always have the capacity of making decisions optimally. Adding expectations to Simon's 
behavioral model, the picture becomes much more complex, since the environment is not "given" (i.e., known to the economic decision maker), but it must incorporate the processes of acquiring knowledge about the environment. At the same time, Simon's behavioral model aims to include decision makers' learning, estimating, searching, and information-processing (Simon, 1958). Indeed, search and satisfying represent two central and related concepts (Note 7) that characterize the mechanisms of choice under bounded rationality (Simon, 1979, p.502). Finally, the theory of problem solving (Newell \& Simon, 1972), which assumes an information processing framework and makes use of computer simulation as a central tool for expressing and testing theories, fits also within the framework of bounded rationality.

\section{Simon's Behavioral Model of Rational Choice}

Simon outlines a formalized behavioral model of rational choice in his article A Behavioral Model of Rational Choice (1955). In this work, he proposes a new kind of rational behavior that must be compatible with information access and computational capacities the organisms (i.e., decision makers), including man, actually possess in the kinds of environments in which such organisms exist (Simon, 1955, p.99). Simon aims to construct definitions of "rational choice" that are modeled more closely upon the actual decision processes of group of individuals, who are making decisions in an organizational context.

Essentially, Simon analyzes the implications of suboptimal decision making through the mathematical methodology of traditional economics.

Simon highlights that the models which are usually based on global rationality and the models of limited (bounded) rationality he suggests generally require some or all of the following elements (Simon, 1955):

1. "A set of behavior alternatives (i.e., alternatives of choice or decision) represented by a point set $A$ " (p.102).

2. "The subset of behavior alternatives that the economic agent (i.e., the individual or the organization) 'considers' or 'perceives'. This subset can be represented by a point set $A^{\square}$, with $A^{\square}$ included in $A\left(A^{\square} \square\right.$ A)" (p.102).

3. "The possible future state of affairs, or outcomes of choice, represented by a point set $S$ " (p.102).

4. 'A 'pay-off' function, representing the 'value' or 'utility' placed by the organism [agent] upon each of the possible outcomes of choice. The pay-off is represented by a real function $V(s)$ which is defined for all elements $s$ of $S$ " (p.102).

5. "Information as to which outcomes in $S$ will actually occur if a particular alternative $a$ in $A$ (or in $A^{\square}$ ) is chosen". This information may be incomplete-that is, more than one possible outcome $s$ for each behavior alternative $a$ may occur. The information is, then, represented by a mapping of each element $a$ in $A$ upon a subset $S_{a}$-the set of outcomes that may ensue if $a$ is the chosen behavior alternative" (p.102).

6. "Information as to the probability that a particular outcome will ensue if a particular behavior alternative is chosen. This is a more precise kind of information than that postulated in (5), as it associates with each element $s$ in the subset $S_{a}$ a probability $\mathrm{P}_{\mathrm{a}}(s)$-the probability that $s$ will occur if $a$ is chosen. The probability $\mathrm{P}_{\mathrm{a}}(s)$ is a real and nonnegative function with $\sum_{s a} \mathrm{~Pa}(s)=1$ ” (p.102).

Simons draws attention on the set of behavior alternatives $A$, the set of outcomes or future states of affairs $S$, and the pay-off $V$. In representing the pay-off matrix of a reduced form game, the set $S$ corresponds to the cells of the matrix, the set $A$ to the strategies of the first player, and the function $V$ to the values in the cells. The set $S a$ is then the set of cells in the $a_{\mathrm{th}}$ row (Simon, 1955, pp. 102-103).

Simon recalls the rational choice procedures which are usually used in the ordinary game-theoretical and probabilistic models which Arrow (1951) cites. He criticizes the "classical" concepts of rationality make severe demands upon the choosing organism (Simon, 1955, p.103) (Note 8). Simon also states that there is a complete lack of evidence that, in actual human choice situations of any complexity, the computations that should be performed in the procedures of "classical" rationality can be really performed (Note 9).

Moreover, Simon introduces the concept of "aspiration level" drawn by psychological theory to fix the boundary between a satisfactory and unsatisfactory pay-off value taken by $V(s)$ (Note 10). Therefore, he examines a different procedure by introducing some modifications that appear (on the basis of casual empiricism) to correspond to observed behavior processes in humans, and that lead to substantial computational simplifications in the making of choice.

The first simplification Simon adopts is to assume simple pay-off functions. Another simplification concerns the information gathering, so that, with a new procedure, the decision maker, "instead of seeking for the "best" move, 
needs only to look for a "good" move" (Simon, 1955, p.108). This means that agents choose on the basis of a strategy that tries to meet adequacy criteria ("good enough"), rather than identifying an optimizing solution. It follows that by the introduction of a simple pay-off function and a process for gradually improving the mapping of behavior alternatives upon possible outcomes, Simon shows that "the process of reaching a rational decision may be drastically simplified from a computational standpoint" "(Simon, 1955, p.108).

Thus, the extension of the notion of a simplified pay-off function permits Simon to find satisfactory solutions in terms of pay-off for the same cases of rational choice in ordinary game-theoretical models. The model outlined above is a fairly complete static case.

Simon also describes one extension of model into dynamics by considering a sequence of situations where the aspiration level, which defines a satisfactory alternative, may change from point to point in the sequence of trials (Note 11).

The central argument of this paper is that the decision maker has limitations on his/her knowledge and capabilities (e.g., in general, he/she does not know the costs of discovering the satisfactory alternatives in the sequence), hence less global models of rationality are significant and useful (Simon, 1955, p. 112). Thus, the decision maker with limited knowledge and ability simplifies the representation of the real world for purposes of choice.

The concept of bounded rationality underlying Simon's view is therefore intended to encompass the idea of the practical impossibility of exercise of global rationality and not of its logical impossibility (Barros, 2010, p. 460). This model represents the core of his behavioral theory of choice based on bounded rationality.

\subsection{Satisficing and the Environment in Simon's Behavioral Model}

Neoclassical economics represents any decision maker as able to solve extremely complex optimization problems. According to this theoretical view, the decision maker is able to extract all the relevant information from the surrounding environment, to process them and find the best response to the problem. He is also able to make, in the environment in which he lives, the best adaptation for his needs and wishes. Simon (1956), in Rational Choice and the Structure of the Environment, strengthens his alternative behavioral approach to the classical model of rational choice. An alternative approach (Simon, 1956, p.138)) "that is more closely related to psychological theories of perception and cognition, and that is in closer agreement to the facts of behavior as observed in laboratory". Simon, therefore, proposes his fundamental theoretical thesis, which he draws on psychology, that organisms adapt well enough to satisfice, instead of optimize.

When Simon talks about the satisficing criterion for problem solving, he is referring to the type of procedure whose fundamental elements can be summarized as follows: The identification of alternatives, heuristic research using a stop rule, and the existence of aspiration levels.

For Simon to use this type of procedure, it means using a type of particular rationality, namely bounded rationality.

He also stresses the relevance of the environment to which the organism must adapt (Simon, 1956). More specifically, the problem of behaving approximately or adaptively in a particular environment (Simon, 1955) and the simplifications that are suitable depend not only on the characteristics of the organism, but equally upon the structure of the environment. Given the computational limits, the environment, of which the actual man is aware (i.e., the subjective perception of the environment), is only a fraction of the "real" environment within which decisions are made.

Simon (1959) stresses the complexity of the environment and the need to know more about the mechanisms man uses to relate himself to that environment and achieve his goals.

Furthermore, as Simon explains (1979, p.510), rational human behavior cannot be accounted for by assuming perfect adaptation to the environment. On the contrary, human behavior operates with relatively simple mechanisms in interaction with extremely complex boundary conditions, which are imposed by the environment and by the capacity of human beings to learn.

Simon is aware of the fact that the number of possible alternatives is immense. This is why he aims at identifying a simple mechanism of choice that would suffice for the behavior of an organism that is confronted with multiple goals, within a psychological environment with some typical structural characteristics. He aims at a choice mechanism that will lead the organism to pursue a satisficing path at some specified level of all its needs (Simon, 1956, pp.136-137).

In short, the rationality of human and organization behavior is always bounded by several limitations. Indeed, bounded rationality is limited by the available information, the tractability of the decision problem, the cognitive 
limitations of individual minds, and the time available to make the decision. In fact, the cognitive limits of knowledge, the computational limits and the impossibility of considering too many variables at the same time, the internal uncertainty of each hierarchy of preferences, the mental disposition, and the various social conditioning make decision makers decide, in most cases, on the basis of a criterion of sufficiency and minimal satisfaction. Also, the environment has a complex structure and is characterized by incomplete information and uncertainty. A successful behavioral approach to studying decision making must take into account the individual's complex relations in the environment. Hence, the decision making that takes place within this environment must consider not only the organism's perception of it, but also its structure. In addition, the decision making aims at satisficing, rather than optimizing.

\section{Procedural Rationality and the Bounded Rationality Theory}

Simon made further attempts to refine his theory of bounded rationality. In the 1950s and 1960s Simon's research aimed at studying the computational limits of human decision makers, also in order to better qualify the notion of bounded rationality. He gave significant contributions on computer science with Allen Newell and John Cliff Shaw, by developing the first heuristic programs and establishing the field of artificial intelligence (Note 12). Simon's idea was to analyze and extend the boundaries of artificial intelligence with particular concern for the simulation of human thought processes. Since rationality is limited by man's computational capabilities, the advances in artificial intelligence have greatly increased man's capacity to manage information, make computations, and solve problems. Simon (1978, p.3) realized that the result of research in artificial intelligence and cognitive psychology gave important advances in understanding choice processes and deepening the understanding of the dynamics of rationality, but also the influences upon choice of the institutional structure within which it takes place.

Human thought processes became, therefore, the focus of his theorizing (Simon, 1978) and artificial intelligence was part of this theorizing.

In the essay From Substantive to Procedural Rationality, Simon (1976) adds an important piece to his theory of bounded rationality, drawing on psychology. Thus, instead of adopting the concept of substantive rationality, typical of neoclassical economics, which extends the rationality to choice outcomes and therefore rationalizing the decision, Simon adopts the concept of procedural rationality. Rational behavior is procedural in the sense that rationality is confined to choice procedures, and procedures, as Barros (2010, p.466) underlines, are algorithms. Simon shows that procedural rationality explains the rationality of the process or processes that are used to arrive at the decision. "Procedural rationality depends on the process that generated it" (Simon, 1976, p.131). In other words, the procedural rationality is able to demonstrate the thought processes which are used to come to the decision. Thus, procedural rationality is a form of rationality with psychological traits, which constitutes a basic concept of Simon's behavioral theory of choice (Barros, 2010; Graziano, \& Schilirò, 2011; Schilirò, 2012).

Simon's procedural rationality to analyze decisions is based on the information-processing approach. As Simon (1976) explains:

"Procedural rationality is usually studied in problem situations-situations in which the subject must gather information of various kinds and process it in different ways in order to arrive at a reasonable course of action, a solution to the problem" (p. 132).

The central question regarding procedural rationality is computational. Since individuals have limited information-processing capacity, they avoid excessive computations. In this regard, Simon recalls the empirical evidence and studies several scholars, including Kahnemann and Tversky (1973) (Note 13), conducted. Simon (1976, p.135) claims that for most problems the individual encounters in the real world, no procedure that he/she can carry out with his/her information processing equipment will enable him/her to discover the optimal solution, given the enormous complexity of the world, even when the notion of optimum is well defined. Boundedly rational decision making necessarily involves non-optimizing procedures (Selten, 1999). Thus, in Simon's view, the search for computational efficiency becomes a search for procedural rationality.

The focus on procedural rationality translates into a focus on the actual processes of cognition and the limits that characterize these processes. Uncertainty and complexity that characterize the decision-making process are the two factors that make the shift towards procedural rationality necessary and inevitable. The shift to procedural rationality is also a shift from concern for optimal solutions to concern for good solutions (Simon, 1976, p.133). The move from neoclassical economics, its notion of substantive rationality, and its oversimplified assumptions implies the adoption of economic behavioralism (Note 14). In this different economic approach, some behavioral premises are injected into the economic theory of decisions, where the decision maker's rationality is 
characterized by limits (i.e., rationality is bounded) and procedural rationality becomes the new notion of rationality (Simon, 1976, p.147).

Simon has therefore developed a behavioral economic theory. This theory involves an explicit link between economics and psychology, and the adoption of the notion of procedural rationality. Since economics tends to explain the decision maker's behavior in complex and dynamic circumstances that involve great uncertainty, a theory of procedural rationality is necessary (Simon, 1978, p.14). Simon believes that this can be done through a complementary approach of several social science, such as operations research, artificial intelligence, cognitive psychology and, naturally, economics.

According to Simon, rational behavior requires simplified models that include the essential elements of the problem, without reflecting all the complexity. Thus, an important aspect of Simon's behavioral theory of rational choice is the adoption of heuristics. Indeed, in order to find good solutions, Simon suggests that decision makers employ heuristics to make decisions, rather than a strict rigid rule of optimization. In Simon's view, the term "heuristic" corresponds to a satisfactory procedure, which is often applied almost automatically and with a reasonable degree of reliability, although it also allows the decision maker to achieve, without consuming excessive time and cognitive resources, a goal that he/she had in mind. Thus, decision makers adopt heuristics because of the complexity of the situation, and their inability to process and compute the expected utility of every alternative action Note 15). Simon also adds that the theory of heuristic search, which is cultivated in artificial intelligence and information processing psychology, is concerned with devising search procedures that will permit systems of limited computational capacity to make complex decisions and solve difficult problems (Simon, 1978, p.12).

Hence, individuals depend on simple heuristics, which adapt choice behavior to their capacity limitations (Myers \& Papageorgiou, 1997).

Moreover, complexity requires decision makers to pay more attention to the procedural aspects of rationality. Simon (1978, p.9) claims that a theory of rational behavior must be concerned with the characteristics of the rational actors as with the characteristics of the objective environment in which they make their decisions. In such a world, procedural rationality-the effectiveness, in light of human cognitive powers and limitations, of the procedures used to choose actions-becomes relevant. In fact, the study of procedural rationality becomes challenging when problems are extremely complex, crucial information is absent, and attention is scarce.

Simon (1978) also highlights the importance of the theory of search for the bounded rationality theory, since the theory of search is concerned with limits on the ability of the decision maker to discover what behavior is optimal for him/her. Simon (1957) describes decision making as a search process guided by aspiration levels (Note 16). Actually, according to Simon (1978, the theory of search must be set within a satisficing model:

"In a satisficing model, search terminates when the best offer exceeds the aspiration level that itself adjusts gradually to the value of the offers received so far" (p.10).

Thus, the theory of search becomes another important piece of Simon's positive theory of bounded rationality.

In conclusion, in Simon's view, human beings have problems in understanding the complexity of the environment. Problems in information processing occur, since perceived information does not always reflect what objectively exists. Simon rejects the hypothesis of optimizing behavior in all cases, except in the simplest ones, while he claims that a decision maker's behavior must be analyzed through his/her thought process. Procedural rationality helps to demonstrate the thought processes used to come to the decision in a complex, uncertain, and changing world. In this regard, the role of knowledge and experience in the individuals' choices is important. Simon (1997b) stresses that choices are determined not only by coherent objectives and properties of the external world. Choices are also determined by the knowledge decision makers possess or do not possess of the world, by their ability or inability to evoke such knowledge at the right time, to elaborate consequences of one's actions, to foresee the possible course of events, to face uncertainties, including the uncertainty deriving from the possible reactions of other agents, and to choose between one's own needs in competition with each other.

Therefore, according to Simon, $(1978,1979)$, a behavioral economic theory which is based on the concept of bounded rationality is characterized by selective search, satisficing, and procedural rationality.

\section{Assessing Bounded Rationality in Simon}

Simon questioned the economic theory based on global rationality for its lack of realism. The realism of the assumptions and the empirical relevance of the theoretical model of rational choice are critical points, in Simon's view (1997a). Empiricism, in particular, constitutes his methodological frame and it is the element that remained 
constant in his works, leading him to introduce psychological factors to explain economic agents' behavior in his bounded rationality model. Furthermore, Simon (1999) considers bounded rationality an important notion not only for economics, but also for his contributions to organization theory, psychology, and computer science.

An important aspect of bounded rationality is that it is instrumental in nature, so it is essentially adopted for solving problems, which often exhibit a logical form.

Another point concerns Simon's success and the relevance of his theoretical stand. In this regard, Simon confronts the theories of global rationality on their field, using formal mathematical models, particularly in one of his works (Simon, 1955). However, this does not prevent him from considering psychological elements.

A controversial point regarding the assessment of Simon's theoretical contribution is the relation between his bounded and procedural rationality concepts. Barros (2010) observes:

"Bounded rationality and procedural rationality are used by him as complementaries. Bounded rationality is essentially a construction in negative: it is the negation of global rationality. It is marked, above all, by its low degree of specificity. The second one embodies, from a theoretical point of view, Simon's positive contributions to the concept of rationality" (pp.469-470).

Also, Barros (2010, p.470) underlines that bounded rationality mostly played a critical role to neoclassical economics, while procedural rationality best expresses the concept of rational behavior, in Simon's studies. Then in Barros' view, Simon's bounded rationality is "a derivate concept" (Barros, 2010, p.460), because Simon (1955, $1956,1957)$ defines bounded rationality as relative to man's incapacity to exercise global rationality. However, Barros (2010) claims that Simon remains the "father" of the notion of bounded rationality (Note 17).

The author of this paper agrees only partially with Barros's arguments. Bounded rationality has become the central concept of Simon's approach to decision making. In Simon's studies, the development of the concept of bounded rationality leads him to identify three steps: Search, satisficing and procedural rationality. Thus, procedural rationality in Simon's work represents an important qualification of his theory of bounded rationality. Moreover, as Jones (2003) pointed out, "precisely in the 1955 model of Simon bounded rationality became a positive theory of choice, not solely a critique of comprehensive rationality" (p. 396).

Actually, several other scholars have used the concept of bounded rationality, exploiting its lack of specificity and aiming only at a critique of global rationality, without grasping the more proactive aspects of Simon's theory. Thus, many theories adopt the notion of bounded rationality, and this term has become fashionable for disparate views of reasoning (Selten, 1999). In this regard, Klaes and Sent (2005) underlined:

"Bounded rationality is being employed with numerous shades of meaning, and there is little indication of any convergence toward a dominant interpretation. All this has done little harm to the use of the expression as the main currency for conceptualizing limitations to the decision-making capabilities of human actors" (p. 49).

As Aumann (1997) pointed out, no unified theory of bounded rationality exists. Indeed, Aumann had a relevant role in bounded rationality theory, since he stimulated research on modeling bounded rationality in game theory (Note 18). He criticized Simon's work because it was conceptual rather than formal. However, Aumann's aim was to approach bounded rationality in an attempt to strengthen neoclassical economics in contrast to Simon's vision (Sent, 2005). Furthermore, Rubinstein (1998) (Note 19) underlined that the problem with the theoretical construct of bounded rationality is that, while only one course of action is open to an ideal optimizer-decision maker that aims to maximize, namely, the optimum, about as many outcomes for procedural satisficers exist as satisficing procedures exist. In other words, many ways are possible to bounded rationality.

However, in contemporary literature, bounded rationality seems to follow another route with respect to Simon's approach. In particular, in such theories, bounded rationality describes cognitive rational processes as events which are weakly connoted in terms of computation and instrumentality, while, in Simon's view, both computation and instrumentality have a relevant role (Fiori, 2005).

Simon (1978) also claimed that the impact of his notion of bounded rationality among mainstream economists was still limited. Although Jones (1999) acknowledged the limited impact on economics, he pointed out that bounded rationality seemed to have a major impact on institutional economics and other social sciences (e.g., political science) (Note 20). In any case, Simon's bounded rationality transformed decision-making theory across literatures. In fact, bounded rationality has been applied to the study of decision - making about financial investment, but also to the study of politics and to the assessment of public policy. Furthermore, the concept of bounded rationality has been extensively used in medical choices. According to McFall (2015), Simon's emphasis on the constraints of the human decision maker during the decision-making process is integral to many 
models of everyday decision making, including the competing perspectives of heuristic, dual process, and behavioral approaches. One important aspect is his theoretical contribution on problem solving (Newell \& Simon, 1972). In Simon's view, computation matters. Simon's research on "human problem solving" became the core of a wide-ranging theoretical project in which artificial intelligence, economics and cognitive psychology were closely intertwined (Fiori, 2005). Nevertheless, even if Simon's research program in problem solving and expertise offered critical tools for studying decision-making processes that took into account his original notion of bounded rationality, unfortunately, these tools were ignored by the major research paradigms in decision making, such as Kahneman and Tversky's (1973) biased rationality approach (i.e., the heuristics and biases approach). It is well known that Tversky and Kahneman's insights went in a different direction with respect to Simon's theoretical view. Indeed, they started from the rationality assumption of neoclassical economics and next they analyzed departures from that benchmark, without developing an alternative view as Simon tried to do.

A different story is the legacy of Simon's work on bounded rationality and his concept of satisficing to the theoretical strand of "fast and frugal heuristics" program of Gigerenzer and his group of psychologists (Gigerenzer, \& Goldstein, 1996; Gigerenzer, 1997; Gigerenzer \& Selten, 2002; Todd, \& Gigerenzer, 2003) of the Max Planck Institute for Human Development. In this case, the link seems closer. However, bounded rationality is conducted in the field of cognitive psychology and no longer in that of economics. In Gigerenzer's work (e.g. Gigerenzer, 1997), Simon's basic idea that it is necessary to simplify, rather than optimize, models is accepted and solved by the "rules of the thumb" (i.e., rules that work in the real world). Moreover, Gigerenzer and Selten (2002) elaborated Simon's ideas that led them to the notion of "ecological rationality" and "adaptive toolbox". These notions characterized the research program of Gigerenzer and the ABC research group (Gigerenzer \& Todd, 1999), but they do not fit convincingly Simon's theoretical stand.

A final consideration is that Simon's contributions to the theory of bounded rationality represent a major scientific work. However, they seem more like a magnificent unfinished symphony (e.g., Franz Schubert's Symphony No. 8) and are the sign of a transition towards a new approach to economics to be completed.

\section{Conclusions}

This paper focuses on Simon's notion of bounded rationality, since bounded rationality remains the hallmark of his theoretical contribution. The work analyzes in depth Simon's behavioral model of rational choice. It shows that Simon's theory of bounded rationality includes three important steps: Search, satisfying, and procedural rationality.

Simon's bounded rationality theory explains the decisional processes that are adopted when it is not possible to choose the best alternative (i.e., fully optimized solution) because of decision makers' limits in terms of information, cognitive capacity, and attention, and of the complexity of the environment in which decision makers make these decisions. In this environment, the individual searches and tries to make decisions that are good enough (i.e. satisfactory) and that represent reasonable or acceptable outcomes. Bounded rationality is not a derivative concept, but constitutes a basic and primary notion for a positive theory of choice in behavioral terms, linking the economic and the psychological sphere. Moreover, in Simon's studies the computational aspect is very important, as also emotions can be encapsulated in the computational theory. In the bounded rationality approach, Simon does not look at the goal, but at the process that leads to an objective narrative. Hence, in this theoretical vision, the notion of procedural rationality becomes crucial. Finally, the paper offers an assessment of the notion of bounded rationality and its impact on economics and other social sciences. Despite its limited influence upon economics, Simon's bounded rationality has transformed decision making theory across literatures and has had a major impact on institutional economics and other social sciences.

\section{Acknowledgment}

The author thanks Maurizio Lisciandra and Mario Graziano for their comments and observations. The usual disclaimer applies.

\section{References}

Arrow, K. J. (1951). Alternative Approaches to the Theory of Choice in Risk-Taking Situations. Econometrica, 19(4), 404-437. https://doi.org/10.2307/1907465

Aumann, R. (1997). Rationality and Bounded Rationality. Games and Economic Behavior, 21(1-2), 2-14. https://doi.org/10.1006/game.1997.0585

Barros, G. (2010). Herbert A. Simon and the Concept of Rationality: Boundaries and Procedures. Brazilian Journal of Political Economy, 30(3), 455-472. https://doi.org/10.1590/S0101-31572010000300006 
Edwards, W. (1954). The Theory of Decision Making. Psychological Bulletin, 51(4), 380-417. https://doi.org/10.1037/h0053870

Fiori, S. (2005). Simon's bounded rationality. Origins and use in economic theory (Working paper No. 09/2005). Torino: CESMEP, Università di Torino, pp.1-24.

Frantz, R. (2003). Herbert Simon. Artificial Intelligence as a Framework for Understanding Intuition. Journal of Economic Psychology, 24, 265-277. https://doi.org/10.1016/S0167-4870(02)00207-6

Gigerenzer, G. (1997). Bounded Rationality: Models of Fast and Frugal Inference. Swiss Journal of Economics and Statistics, 133(2/2), 201-218.

Gigerenzer, G., \& Goldstein, D. G. (1996). Reasoning the Fast and Frugal Way: Models of Bounded Rationality. Psychological Review, 103(4), 650-669. https://doi.org/10.1037/0033-295X.103.4.650

Gigerenzer, G., \& Selten, R. (2002). Bounded rationality. The adaptive toolbox. Cambridge, MA: MIT Press.

Gigerenzer, G., \& Todd, P. M. (1999). Fast and Frugal Heuristics. The Adaptive Toolbox. In G. Gigerenzer, P.M. Todd, \& the ABC Research Group (Eds.), Simple heuristics Simple heuristics that make us smart (pp.3-34). New York, NY: Oxford University Press.

Graziano, M., \& Schilirò, D. (2011). Rationality and Choices in Economics: Behavioral and Evolutionary Approaches. Theoretical and Practical Research in Economic Fields, 2(2), 183-196.

Howard, R. A. (1960). Dynamic programming and Markov processes, Boston, MA: The M.I.T. Press.

Jones, B. (1999). Bounded Rationality. Annual Review of Political Science, 2(1), 297-321. https://doi.org/10.1146/annurev.polisci.2.1.297

Jones, B. (2003). Bounded Rationality and Political Science: Lessons from Public Administration and Public Policy. Journal of Public Administration Research and Theory, 13(4), 395-412. https://doi.org/10.1093/jopart/mug028

Kahneman, D., \& Tversky, A. (1973). On the Psychology of Prediction. Psychological Review, 80(4), 237-251. https://doi.org/10.1037/h0034747

Klaes, M., \& Sent, E. (2005). A Conceptual History of the Emergence of Bounded Rationality. History of Political Economy, 37(1), 27-59. https://doi.org/10.1215/00182702-37-1-27

Mallard, G. (2016). Bounded rationality and behavioural economics. New York, NY: Routledge.

McFall, J. P. (2015). Rational, Normative, Descriptive, Prescriptive, or Choice Behavior? The Search for Integrative Metatheory of Decision Making. Behavioral Development Bulletin, 20(1), 45-59. https://doi.org/10.1037/h0101039

Myers, G. M., \& Papageorgiou, Y. (1997). Procedural Rationality and the Need to Aggregate. Espace Géographique, 26(2), 153-164. https://doi.org/10.3406/spgeo.1997.1066

Nelson, D. L., \& Campbell Quick, J. (2013). Organizational behavior. Science, the real world and you. $8^{\text {th }}$ edition. Mason, $\mathrm{OH}$ : Cengage Learning.

Newell, A., \& Simon, H. (1972). Human problem solving. Englewood Cliffs, N. J.: Prentice-Hall.

Newell, A., Shaw, J. C., \& Simon, H. (1957). Empirical explorations of the logic theory of machine. Proceedings of the Western Joint Computer Conference, 7, 101-108. https://doi.org/10.1145/1455567.1455605

Rubinstein, A. (1998). Modeling bounded rationality. Cambridge, MA: MIT Press.

Schilirò, D. (2012). Bounded Rationality and Perfect Rationality: Psychology into Economics. Theoretical and Practical Research in Economic Fields, 3(2), 101-111. https://doi.org/10.2478/v10261-012-0007-0

Schilirò, D. (2013). Economics and Psychology. Perfect Rationality versus Bounded Rationality. Contemporary Mathematics, 601, 359-372. https://doi.org/10.1090/conm/601/11955

Schilirò, D. (2017). Economics versus Psychology. Risk, Uncertainty and the Expected Utility Theory. Journal of Mathematical Economics and Finance, 3(1), 77-96.

Selten, R. (1999). What is Bounded Rationality? SFB Discussion Paper B-454, May, 1-25.

Sent, E. (2005). Simplifying Herbert Simon. History of Political Economy, 37(2), 227-232. https://doi.org/10.1215/00182702-37-2-227

Simon, H. (1947). Administrative behavior. A study of decision-making processes in administrative organization. 
New York, NY: Macmillan.

Simon, H. (1955). A Behavioral Model of Rational Choice. The Quarterly Journal of Economics, 69(1), 99-118. https://doi.org/10.2307/1884852

Simon, H. (1956). Rational Choice and the Structure of the Environment. Psychological Review, 63(2), 129-138. https://doi.org/10.1037/h0042769

Simon, H. (1957). Models of man, social and rational: Mathematical essays on rational human behavior in a social setting. New York, NY: Wiley.

Simon, H. (1958). The role of expectations in an adaptive or behavioristic model. In M. J. Bowman (Ed.), Expectations, uncertainty and business behavior. Organizations (pp.49-58). New York: Social Science Research Council.

Simon, H. (1959). Theories of Decision-Making in Economics and Behavioral Science. The American Economic Review, 49(3), 253-283.

Simon, H. (1972). Theories of bounded rationality. In C. B. McGuire \& R. Radner (Eds.), Decision and organization. A volume in honor of Jacob Marschak (pp.161-176). Amsterdam, NL: North-Holland.

Simon, H. (1976). From substantive to procedural rationality. In S. J. Latsis (Ed.), Method and appraisal in economics (pp. 129-148). Cambridge, UK: Cambridge University Press. https://doi.org/10.1017/CBO9780511572203.006

Simon, H. (1978). Rationality as a Process and a Product of Thought. The American Economic Review, Papers and Proceedings, 68(2), 1-16.

Simon, H. (1979). Rational Decision Making in Business Organizations [Nobel Memorial Lecture]. American Economic Review, 69(4), 493-513.

Simon, H. (1987). Bounded rationality. In J. Eatwell, M. Milgate, \& P. Newman (Eds.), The new Palgrave dictionary of economics (pp. 243-245). London, UK: Macmillan. https://doi.org/10.1057/978-1-349-95121-5_472-1

Simon, H. (1990). Invariants of Human Behavior. Annual Review of Psychology, 41, 1-20. https://doi.org/10.1146/annurev.ps.41.020190.000245

Simon, H. (1991). Organization and Markets. The Journal of Economic Perspectives, 5(2), 25-44. https://doi.org/10.1257/jep.5.2.25

Simon, H. (1997a). An empirically based microeconomics. Cambridge, UK: Cambridge University Press.

Simon, H. (1997b). Models of bounded rationality, Volume 3. Empirically grounded economic reason. Cambridge, MA.: MIT Press.

Simon, H. (1999). The potlatch between political science and economics. In J. Alt, M. Levi, \& E. Ostrom (Eds.), Competition and cooperation: Conversations with nobelists about economics and political science (pp.112-119). Cambridge, UK: Cambridge University Press.

Simon, H., Egidi, M., Viale, R., \& Marris, R. (1992). Economics, bounded rationality and the cognitive revolution. Cheltenham, UK: Edward Elgar Publishing.

Todd, P. M., \& Gigerenzer, G. (2003). Bounding rationality to the world. Journal of Economic Psychology, 24, 143-165. https://doi.org/10.1016/S0167-4870(02)00200-3

\section{Notes}

Note 1. Simon was a multidisciplinary author. In 1978, he was awarded the Nobel Prize in economics for his studies on decision making.

Note 2. Ronald A. Howard (1960) is considered one of the fathers of decision analysis together with Howard Raiffa.

Note 3. Global rationality for Simon is the specific form of rationality of the economic man in neoclassical economics, and corresponds to the idea of perfect or omniscient rationality, in contrast to a limited or bounded rationality of the actual man, who has limits in terms of computational and information capacity, and predictive ability (Simon, 1955).

Note 4. The term satisficing is a combination of the words "satisfy" and "suffice". Simon (1959) considers the 
economic man as a satisficing individual whose problem solving is based on search activity to meet certain aspiration levels, rather than a maximizing agent whose problem solving involves finding the best alternatives in terms of specified criteria.

Note 5. The concept of satisficing is common to psychology, while in economics it is assumed to be less important because standard (neoclassical) economics assumes that individuals are maximisers of objectively or globally and substantively rational expected utility. Undoubtedly, these assumptions amount to nothing more than assuming away the importance of satisficing (Frantz, 2003).

Note 6. See also Nelson and Campbell Quick (2013).

Note 7. Since decision makers aim at satisficing, they search for alternatives that are good enough, according to some pre-established criteria.

Note 8 . For instance, the agent must be able to attach definite payoff to each possible outcome, or it must have the ability to specify the exact nature of the outcomes.

Note 9. The "classical" concept of rationality includes the max-min rule, the probabilistic rule, and the certainty rule.

Note 10. The aspiration level criterion selects the alternative that is satisfactory. In addition, the aspiration level can itself adjust upward or downward, on the basis of experience (Simon, 1955, 1959).

Note 11. In the dynamics, the aspiration level at time $t$ depends upon the previous history of the system. Payoff in particular trial may depend not only on the alternative chosen in that trial, but also on alternatives chosen in the previous trials. The consequences that the organism can experience may change the pay-off function. One choice method may be to select a particular alternative and experience its consequences (Simon, 1955, p. 113).

Note 12. Newell, Shaw, and Simon (1957) argued that computers could model human thought. These authors worked together at Rand Corporation, developed the Information Processing Language (IPL), and created the Logic Theorist, which established the field of heuristic programming (Fiori, 2005).

Note 13. Simon cites Kahnemann and Tversky (1973) regarding the fact that in their experiments the individuals do not apply the Bayes's theorem.

Note 14. Simon (1976) acknowledges that a number of developments in economics have taken place toward procedural rationality, as in the real word of business regarding the price setting, in operations research, in oligopoly and imperfect competition theory, and in treating expectations and uncertainty.

Note 15. Gigerenzer and Selten (2002) provided a repertoire of fast and frugal rules (i.e., a type of heuristics) for decision making under uncertainty, in the attempt to impose more order and coherence on the idea of bounded rationality.

Note 16. Selten (1999), in particular, observes that in Simon's work "decision alternatives are not given, but found one after the other in a search process" (p.2).

Note 17. Barros (2010) admits that the use of this concept, which diverse strands in the field of economic science have formulated, very often refers to him.

Note 18. The bounded rationality approach has been applied to the area of refinement of the Nash equilibrium, in the study of the applicability of the folk theorem and in the problem of equilibrium selection (Sent, 2005).

Note 19. Rubinstein (1998) provides a set of elegant mathematical tools to model boundedly rational agents of various sorts. These are: Simplifying decision-making by ignoring "similar" features of incompatible options; limiting knowledge (represented by a formalism borrowed from modal logic); limiting memory; aggregating individual decisions by teams; playing games by means of automata (i.e., limiting game-theoretic strategies to those which can be implemented by abstract automata). However, this approach appears too distant from the empirical and experimental methodology Simon adopts.

Note 20. Simon (1991), however, criticized the new institutional economics as incomplete.

\section{Copyrights}

Copyright for this article is retained by the author(s), with first publication rights granted to the journal.

This is an open-access article distributed under the terms and conditions of the Creative Commons Attribution license (http://creativecommons.org/licenses/by/4.0/). 